Cite this: J. Mater. Chem. A, 2014, 2, 7686

Received 21st February 2014 Accepted 26th March 2014

DOI: 10.1039/c4ta00793j

www.rsc.org/MaterialsA

\title{
Bio-inspired carbon nitride mesoporous spheres for artificial photosynthesis: photocatalytic cofactor regeneration for sustainable enzymatic synthesis $\uparrow$
}

\author{
Jianhui Huang, ${ }^{b}$ Markus Antonietti ${ }^{a}$ and Jian Liu*a
}

\begin{abstract}
Inspired by the photosynthetic thylakoid membrane of chloroplasts, we present here the rational design of mesoporous structured colloids made up of graphitic carbon nitride nanosheets and demonstrate their application in photocatalytic NADH regeneration for sustainable enzymatic synthesis.
\end{abstract}

\section{Introduction}

High efficiency light energy-to-chemical energy conversion is thought to be the ultimate goal in the field of sustainable energy, considering the sustainable and inexhaustible character of sunlight. ${ }^{1}$ In natural photosynthesis, green plants and algae have evolved into highly delicate, complex structures to convert light to chemical energy. Learning from nature might offer some possible key elements for realizing artificial photosynthesis. $^{2-6}$ Inside the photosynthetic factories termed chloroplasts, a membrane-bound thylakoid is the site of the lightdependent reactions of photosynthesis. Following light harvesting by chlorophyll molecules, photoinduced electrons are passed through the electron transport chain to the enzyme ferredoxin-NADP (nicotinamide adenine dinucleotide phosphate) reductase, leading to the reduction of $\mathrm{NAD}(\mathrm{P})$ to $\mathrm{NAD}(\mathrm{P})$ $\mathrm{H}$, completing the storage of light energy in one kind of "energy currency" of the cells (another kind is ATP). The newly formed $\mathrm{NAD}(\mathrm{P}) \mathrm{H}$ is used as a hydrogen source with high reducing power for the biosynthesis of carbohydrates from $\mathrm{CO}_{2}$ in the Calvin cycle of the dark reaction. ${ }^{7} \mathrm{NAD}(\mathrm{P})^{+} / \mathrm{NAD}(\mathrm{P}) \mathrm{H}$ cofactors are also involved in many other enzymatic redox reactions of the metabolism. Recently, applying such enzymatic redox reactions for the synthesis of valuable and chiral compounds in vitro became highly attractive. ${ }^{8-10}$ However, high costs of enzyme-

${ }^{a}$ Department of Colloid Chemistry, Max-Planck Institute of Colloids and Interfaces, Research Campus Golm, 14476 Potsdam, Germany.E-mail: Jian.Liu@mpikg.mpg.de ${ }^{b}$ College of Environmental and Biological Engineering, Putian University, Putian 351100, P.R.China

$\dagger$ Electronic supplementary information (ESI) available: Experimental section, TEM images, $\mathrm{N}_{2}$ sorption isotherm plots, time-resolved photoluminescence, NMR spectra of CNMS can be found in the ESI. See DOI: 10.1039/c4ta00793j specific cofactors (NADH) hinder wider applications, and sustainable and economically acceptable regeneration methods for NADH are still eagerly demanded. ${ }^{11}$

As in the photosynthetic light reactions, using light energy for the reduction of $\mathrm{NAD}^{+}$to $\mathrm{NADH}$ is very promising and inherently sustainable, compared with the established but not optimal enzymatic regeneration method and electrochemical routes. ${ }^{12-16}$ By taking electrons from a light excited photocatalyst and coupling the protons to form the hydride electron pair, the $\mathrm{NAD}^{+}$can be selectively reduced to 1,4-NADH in the presence of $\left[\mathrm{Cp} * \mathrm{Rh}(\mathrm{bpy}) \mathrm{H}_{2} \mathrm{O}\right]^{2+}$ (abbreviated as $\mathbf{M}$ in the following context) acting as a hydride transfer reagent while triethanolamine (denoted as TEOA) is employed as a sacrificial electron donor. ${ }^{17}$ Despite previously reported works on the photocatalytic NADH regeneration, however, more facile and more efficient visiblelight-driven photocatalytic systems are critically needed and are to be developed. ${ }^{18-23}$

Inspired by the folded, layered thylakoid membranes featuring very large surface area, which therefore could increase the amount of light absorbance, construction of a structural mimicry of the thylakoid membranes as a semiconductor object is promising to increase the efficiency of NADH regeneration. ${ }^{24}$ Graphitic carbon nitride (abbreviated as $\mathrm{g}-\mathrm{C}_{3} \mathrm{~N}_{4}$ ) is known as a layered material and found in recent years to possess visiblelight-driven photocatalytic properties..$^{25-32}$ Our previous work demonstrated that a synthetic carbon nitride photosynthetic structure onto diatom frustules could be used for photocatalytic NADH regeneration..$^{33}$ However, the low surface area partly counterbalanced the benefits of refractive light harvesting brought about by the diatom structure. ${ }^{34}$ Higher efficiency could be achieved by coupling a higher specific surface area and strong light harvesting properties. ${ }^{35}$ Carbon nitride will act as the ultimate light-to-charge pair conversion site while a structured mesoporous sphere architecture could enhance the light intensity onto the active centers. ${ }^{36-38}$ The in situ regenerated $\mathrm{NADH}$ is then coupled with L-lactate dehydrogenase for sustainable photoenzymatic synthesis. In addition, as outlined in our previous report, direct transfer of a hydride electron pair 
from carbon nitride to $\mathrm{NAD}^{+}$is also possible, and metal- and mediator free regeneration of $\mathrm{NADH}$ as the ultimate goal will also be investigated. ${ }^{39}$

\section{Experimental section}

\section{Materials synthesis}

Synthesis of CNMS. In a typical synthesis, $5 \mathrm{~mL}$ TEOS was injected into a mixture of $20 \mathrm{~mL}$ of deionized $\mathrm{H}_{2} \mathrm{O}, 5 \mathrm{~mL}$ of $\mathrm{NH}_{3} \cdot \mathrm{H}_{2} \mathrm{O}$ and $100 \mathrm{~mL}$ of 2-propanol at room temperature under magnetic stirring. After reaction for 2 hours, the colloidal spheres were collected by centrifugation and re-dispersed in 150 $\mathrm{mL}$ deionized water. Certain amount of polyvinylpyrrolidone (PVP) K15 $\left(M_{\mathrm{w}} \sim 10000\right)$ was added to the above $\mathrm{SiO}_{2}$ solution. The mixture was heated up to $100{ }^{\circ} \mathrm{C}$ and kept for 3 hours under refluxing to load $\mathrm{PVP}$, and then cooled to room temperature. Under magnetic stirring, $37.5 \mathrm{~mL}$ of $0.1 \mathrm{~g} \mathrm{~mL}^{-1}$ sodium hydroxide aqueous solution was added to the as-cooled solution at room temperature. As more material is etched away from the silica particles, the solution becomes less and less opaque. The etching process could be monitored by measuring transmission of the etching solution at $700 \mathrm{~nm}$ using UV-Vis spectrometry. A mixture of $1 \mathrm{~g}$ of etched $\mathrm{SiO}_{2}$ mesoporous sphere and $5 \mathrm{~g}$ of cyanamide was degassed for 3 hours followed by sonication in water for 2 hours. After removal of surplus cyanamide by dissolving in water, the obtained white solid was transferred to a crucible with lid and heated under air at $2.3{ }^{\circ} \mathrm{C} \min ^{-1}$ up to $550{ }^{\circ} \mathrm{C}$ ( 4 hours) and kept at $550{ }^{\circ} \mathrm{C}$ for another 4 hours. The resultant yellow powder is treated with a $4 \mathrm{M} \mathrm{NH}_{4} \mathrm{HF}_{2}$ solution for 48 hours. The dispersion is then filtered and the yellow precipitate is copiously rinsed with deionized water and ethanol. Finally, the yellow powder is dried under a vacuum at $60{ }^{\circ} \mathrm{C}$ overnight.

Synthesis of $\left[\mathbf{C p} * \mathbf{R h}(\mathbf{b p y}) \mathrm{H}_{2} \mathrm{O}\right]^{2+} \cdot \mathrm{RhCl}_{3} \cdot \mathrm{H}_{2} \mathrm{O}$ is refluxed in methanol with one equivalent of 1,2,3,4,5-pentamethylcyclopentadiene for 24 hours. The resulting red precipitate is filtered and suspended in methanol. On addition of two equivalents of 2,2-bipyridine, the suspension clears up immediately and a yellowish solution is formed. [Cp* $\mathrm{Rh}(\mathrm{bpy}) \mathrm{Cl}] \mathrm{Cl}$ is precipitated on the addition of diethyl ether into the obtained yellowish solution. Stock solutions (100 mM) are prepared in water and stored at room temperature avoiding direct light exposure. [Cp* $\mathrm{Rh}(\mathrm{bpy}) \mathrm{Cl}] \mathrm{Cl}$ readily hydrolyzes to $\left[\mathrm{Cp} * \mathrm{Rh}(\mathrm{bpy})\left(\mathrm{H}_{2} \mathrm{O}\right)\right]^{2+}$.

\section{Characterization}

XRD measurements were performed on a D8 Diffractometer from Bruker instruments ( $\mathrm{Cu} \mathrm{K} \alpha$ radiation, $\lambda=0.154 \mathrm{~nm}$ ) equipped with a scintillation counter. $\mathrm{N}_{2}$ sorption experiments were done with a Quantachrome Autosorb-1 at liquid nitrogen temperature. TEM images were taken on Philips CM200 FEG (Field Emission Gun), operated at an acceleration voltage of 200 $\mathrm{kV}$. SEM measurement was performed on a LEO $1550 \mathrm{Gemini}$ instrument. The UV-Vis absorbance spectra were recorded on a T70 UV/Vis spectrophotometer. The FTIR spectrum was collected using a Varian 1000 FTIR spectrometer.
Electrochemical analysis. The working electrode was prepared on indium-tin oxide (ITO) glasses, which was cleaned by sonication in chloroform, acetone and ethanol for $30 \mathrm{~min}$, respectively. The glass was then rinsed with Millipore water and kept in isopropanol for $24 \mathrm{~h} .50 \mathrm{mg}$ powder was mixed with $2 \mathrm{~mL}$ dimethylformamide under sonication for $30 \mathrm{~min}$ to get a slurry. The slurry spread onto ITO glass whose side part was previously protected using Scotch tape. After air drying, the electrode was fired at $350{ }^{\circ} \mathrm{C}$ for $30 \mathrm{~min}$ in air to improve adhesion. A copper wire was connected to the side part of the ITO glass using a conductive tape. Uncoated parts of the electrode were isolated with epoxy resin, and the exposed area of the electrode was $0.25 \mathrm{~cm}^{2}$. Electrochemical measurements were performed in a conventional three electrode cell, using a Pt plate and a $\mathrm{Ag} / \mathrm{AgCl}$ electrode $(3 \mathrm{M} \mathrm{KCl})$ as counter electrode and reference electrode, respectively. The electrolyte was a $0.2 \mathrm{M} \mathrm{Na}_{2} \mathrm{SO}_{4}$ aqueous solution without additives and was purged with nitrogen gas for $2 \mathrm{~h}$ prior to the measurements. The working electrodes were immersed in the electrolyte for $60 \mathrm{~s}$ before any measurement was taken. The photocurrent measurements were conducted with a BAS epsilon workstation, with the working electrodes irradiated from the back side in order to minimize the influence of thickness of the semiconductor layer. The light was generated by a $500 \mathrm{w}$ xenon lamp (Changtuo, CHF-XM500) with a $420 \mathrm{~nm}$ cut-off filter, and was chopped manually $(\approx 0.20 \mathrm{~Hz})$. The electrochemical impedance spectroscopy experiments were conducted on a Precision PARC workstation. For Nyquist plot measurements, the perturbation signal was also $20 \mathrm{mV}$ but the frequency ranged from $200 \mathrm{kHz}$ to $10 \mathrm{mHz}$.

\section{NADH regeneration and photoenzymatic reaction}

NADH regeneration. In a typical regeneration procedure, the reaction medium was composed of $\mathrm{NAD}^{+}(1 \mathrm{mM})$, TEOA (15 w/v\%), phosphate buffer $(100 \mathrm{mM})$ and carbon nitride materials. The $\mathrm{pH}$ value of the reaction media was set to 8 or 10 for a mediator involved or mediator free system, respectively. The reaction system was placed into a quartz reactor equipped with a stirring bar and illuminated with a LED lamp (wavelength $=420 \mathrm{~nm}$, OSA Opto Light $\mathrm{GmbH}$ ). The distance between reactor and LED lamp is fixed at $5 \mathrm{~cm}$. Before the illumination, the reaction solution was placed in a dark environment for certain minutes to achieve adsorption-desorption equilibrium. During the illumination, the concentration of $\mathrm{NADH}$ was calculated by measuring the absorbance of the diluted reaction system at $340 \mathrm{~nm}$. NAD ${ }^{+}$has peak absorption at a wavelength of $260 \mathrm{~nm}$, with an extinction coefficient of $16900 \mathrm{M}^{-1} \mathrm{~cm}^{-1}$. $\mathrm{NADH}$ has peak absorption at $340 \mathrm{~nm}$ with an extinction coefficient of $6220 \mathrm{M}^{-1} \mathrm{~cm}^{-1}$.

Photoenzymatic reaction. The reaction medium for the photoenzymatic reaction includes $\mathrm{NAD}^{+}(1 \mathrm{mM}), \mathrm{M}(0.25 \mathrm{mM})$, pyruvate $(5 \mathrm{mM})$, L-lactate dehydrogenase $(50 \mathrm{U}), \mathrm{pH}=7.0$ phosphate buffer with $15 \mathrm{w} / \mathrm{v} \%$ TEOA, $3 \mathrm{mg}$ CNMS. The reaction solution was stirred in the dark for one hour followed by 6 hour light reaction. 


\section{Results and discussion}

Carbon nitride mesoporous spheres (abbreviated as CNMS) were synthesized by templating etched silica spheres, adopting a strategy termed "silica-etching chemistry", as illustrated in Scheme $1 .{ }^{40}$ Briefly, the $\mathrm{SiO}_{2}$ sphere was first loaded with polyvinylpyrrolidone (PVP) for protecting an outside $\mathrm{SiO}_{2}$ shell, and a sodium hydroxide solution mildly etches the dense silica sphere towards a mesoporous system. These etched mesoporous structures then provide confined and necessary space for loading the cyanamide precursor for the subsequent in situ thermal condensation towards carbon nitride. At last, after removing the silica template by an aqueous $\mathrm{NH}_{4} \mathrm{HF}_{2}$ solution, a CNMS preserving the original sphere size, but with inverted inner structure could be obtained. ${ }^{26}$ In general, the moderation and control of the silica-etching chemistry is the determining factor for the successful construction of CNMS. The degree of etching can be facilely controlled by the etching time; an appropriate etching end point can be quantitatively determined by an increase of the original optical transmission at $700 \mathrm{~nm}$ wavelength up to $70 \%$. The morphology evolution of a $\mathrm{SiO}_{2}$ sphere during different etching times was investigated, as illustrated in Fig. S1 (ESI $\dagger$ ). Different etching degrees of $\mathrm{SiO}_{2}$ lead to entirely different morphologies of the obtained carbon nitride materials. As it is templated from the original $\mathrm{SiO}_{2}$ sphere or $\mathrm{SiO}_{2}$ sphere with low etching degree, only fragments and no defined particles could be obtained.

Scanning electron microscopy (SEM) and transmission electron microscopy (TEM) images in low magnification for a large area overview of CNMS demonstrate the high homogeneity and uniformity of the obtained spherical material, as shown in

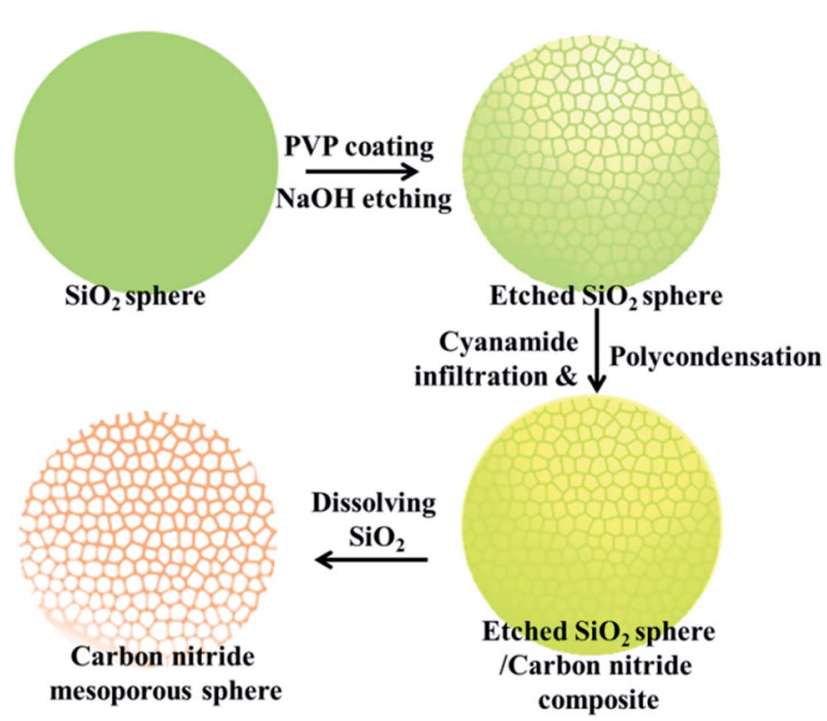

Scheme 1 Schematic fabrication strategy for CNMS. The whole processes could be divided into four steps: (1) synthesis of a $\mathrm{SiO}_{2}$ sphere; (2) loading with PVP under refluxing conditions and mildly etching PVP coated $\mathrm{SiO}_{2}$ with $\mathrm{NaOH}$ to obtain mesoporous $\mathrm{SiO}_{2}$; (3) loading a cyanamide precursor into the porous space followed by in situ thermal condensation to carbon nitride; and (4) using an $\mathrm{NH}_{4} \mathrm{HF}_{2}$ aqueous solution to release CNMS.
Fig. 1a and b, and the local structure was evidenced by the TEM image shown in Fig. 1c. The CNMS was chosen to have a diameter around $420 \mathrm{~nm}$ to enable multiple internal light reflections and consequently higher light absorbance. The size matches with the peak wavelength of the blue LED light source which also is near the onset of optical absorbance of g- $\mathrm{C}_{3} \mathrm{~N}_{4}$. The original $\mathrm{SiO}_{2}$ and etched $\mathrm{SiO}_{2}$ spheres are compared to those replicated structures in Fig. 1d \& e, while the corresponding SEM images along with a large overview of CNMS are displayed in Fig. S2 of the ESI, $\uparrow$ respectively. Throughout etching, the PVP protected $\mathrm{SiO}_{2}$ spheres do not decrease in diameter. The solid spheres turn mesoporous with the coarsened surface while still preserving the spherical morphology, indicating that the etching process is prohibited by the PVP protection of the shell. Compared with the sphere template, the size of obtained CNMS is a little smaller due to the shrinkage throughout thermal condensation. The typical material characterization results for CNMS are presented in Fig. S3 of the ESI. $\dagger$ The band at $810 \mathrm{~cm}^{-1}$ in the Fourier transform infrared spectroscopy (FTIR) spectra in Fig. S3a of the ESI $\dagger$ is ascribed to the $s$-triazine ring modes, while the bands at $1200-1600 \mathrm{~cm}^{-1}$ are characteristic of aromatic $\mathrm{CN}$ heterocycles. A powder X-ray diffraction (XRD) spectrum shows the two characteristic peaks of graphitic carbon nitride (Fig. S3b of the ESI $\dagger$ ) at $13.0^{\circ}$ and $27.4^{\circ}$ which are ascribed to the in-plane repeat period and stacking of the conjugated aromatic system, respectively. $\mathrm{N}_{2}$ sorption measurement reveals that the CNMS is indeed mesoporous, with a specific surface area of $205 \mathrm{~m}^{2} \mathrm{~g}^{-1}$ (see Table 1, Fig. S3 and 4 of the ESI†).

The (photo)electrochemical properties of CNMS accompanying two control samples (bulk g- $\mathrm{C}_{3} \mathrm{~N}_{4}$ and $\mathrm{mpg}$ - $\mathrm{C}_{3} \mathrm{~N}_{4}$ ) were investigated by electrochemical impedance spectroscopy (Fig. 2a). The results revealed semicircular Nyquist plots for CNMS, mpg- $\mathrm{C}_{3} \mathrm{~N}_{4}$ and $\mathrm{g}-\mathrm{C}_{3} \mathrm{~N}_{4}$ with the trend of increasing

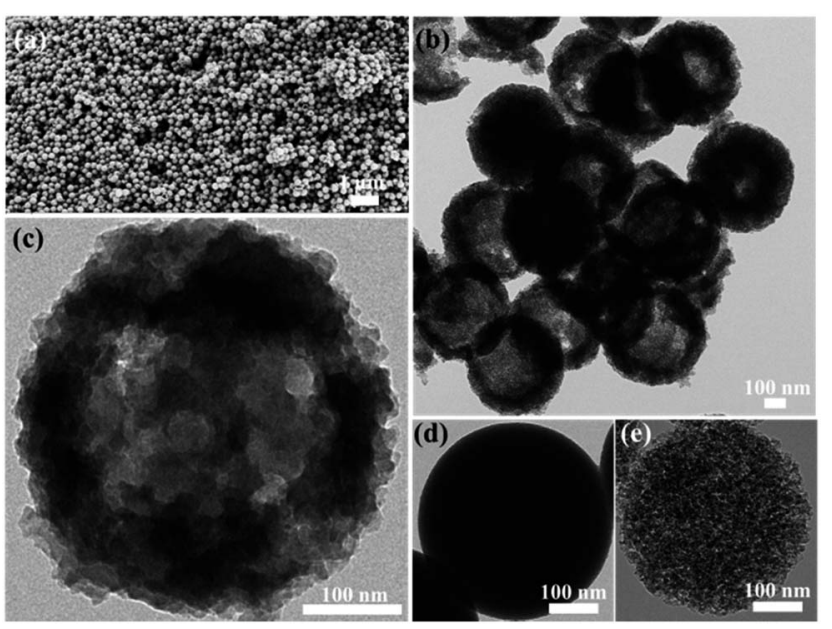

Fig. 1 (a) SEM image of large area overview, illustrating the uniform and monodisperse properties of CNMS. (b) TEM image of CNMSs. (c) TEM image of a single CNMS particle, showing the porous property and nanosheet as the building blocks of CNMS. (d) and (e) show the TEM images of original solid $\mathrm{SiO}_{2}$ sphere and etched mesoporous $\mathrm{SiO}_{2}$ sphere, respectively. 
Table 1 Textural properties of $\mathrm{g}-\mathrm{C}_{3} \mathrm{~N}_{4}$ prepared under different conditions

\begin{tabular}{llcc}
\hline Sample & Bulk g-C $\mathrm{C}_{3}$ & mpg- $\mathrm{C}_{3} \mathrm{~N}_{4}$ & CNMS \\
\hline Surface area $^{a}\left(\mathrm{~m}^{2} \mathrm{~g}^{-1}\right)$ & 12 & 230 & 205 \\
Pore volume $^{b}\left(\mathrm{~cm}^{3} \mathrm{~g}^{-1}\right)$ & 0.21 & 0.765 & 0.51 \\
C/N ratio $^{c}$ & 0.676 & 0.679 & 0.682 \\
Hydrogen content $^{d}(\%)$ & 2.06 & 2.45 & 2.31
\end{tabular}

${ }^{a}$ BET surface area. ${ }^{b}$ Barrett-Joyner-Halenda (BJH) adsorption pore volume. ${ }^{c}$ Molar ratio. ${ }^{d}$ Weight ratio.

diameter, which demonstrated that CNMS possessed an improved electronic conductivity already in the dark state as compared to the other morphologies. The photoinduced electron transfer processes were also investigated. The photocurrent measurements of the three materials cast on indium tin oxide glass were conducted in a $0.2 \mathrm{M} \mathrm{Na}_{2} \mathrm{SO}_{4}$ aqueous solution (Fig. 2b). Large enhancement of $I_{\mathrm{ph}}$ for CNMS was indeed observed over an applied bias potential of $0.4 \mathrm{~V}$ versus $\mathrm{Ag} / \mathrm{AgCl}$, indicating strong light harvesting capability and faster transport of charged carriers.

Fig. 3a shows the diffuse reflectance spectra of the obtained materials, indicating typical semiconductor absorption
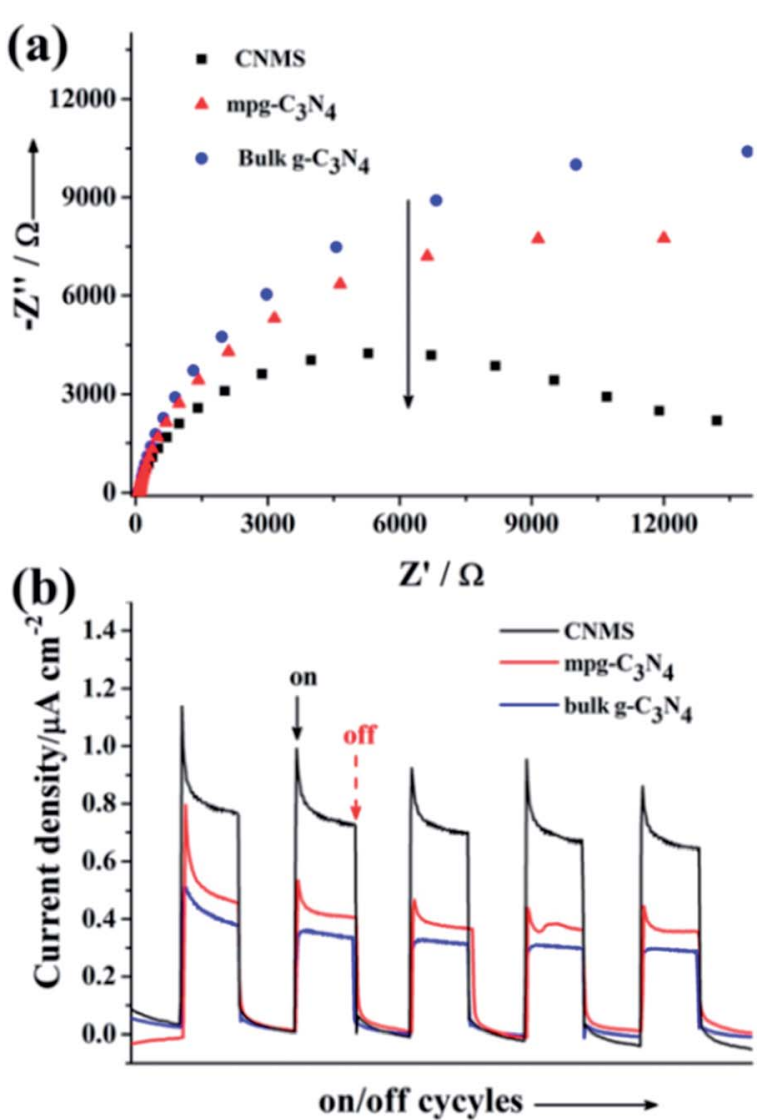

Fig. 2 (a) Electrochemical impedance spectroscopy Nyquist plots for CNMS, mpg- $\mathrm{C}_{3} \mathrm{~N}_{4}$ and $\mathrm{g}-\mathrm{C}_{3} \mathrm{~N}_{4}$, respectively. (b) The periodic on/off photocurrent output of CNMS, mpg- $\mathrm{C}_{3} \mathrm{~N}_{4}$ and $\mathrm{g}-\mathrm{C}_{3} \mathrm{~N}_{4}$ cast on ITO glass at $0.4 \mathrm{~V}$ bias vs. $\mathrm{Ag} / \mathrm{AgCl}$ in a $0.2 \mathrm{M} \mathrm{Na}_{2} \mathrm{SO}_{4}$ solution.
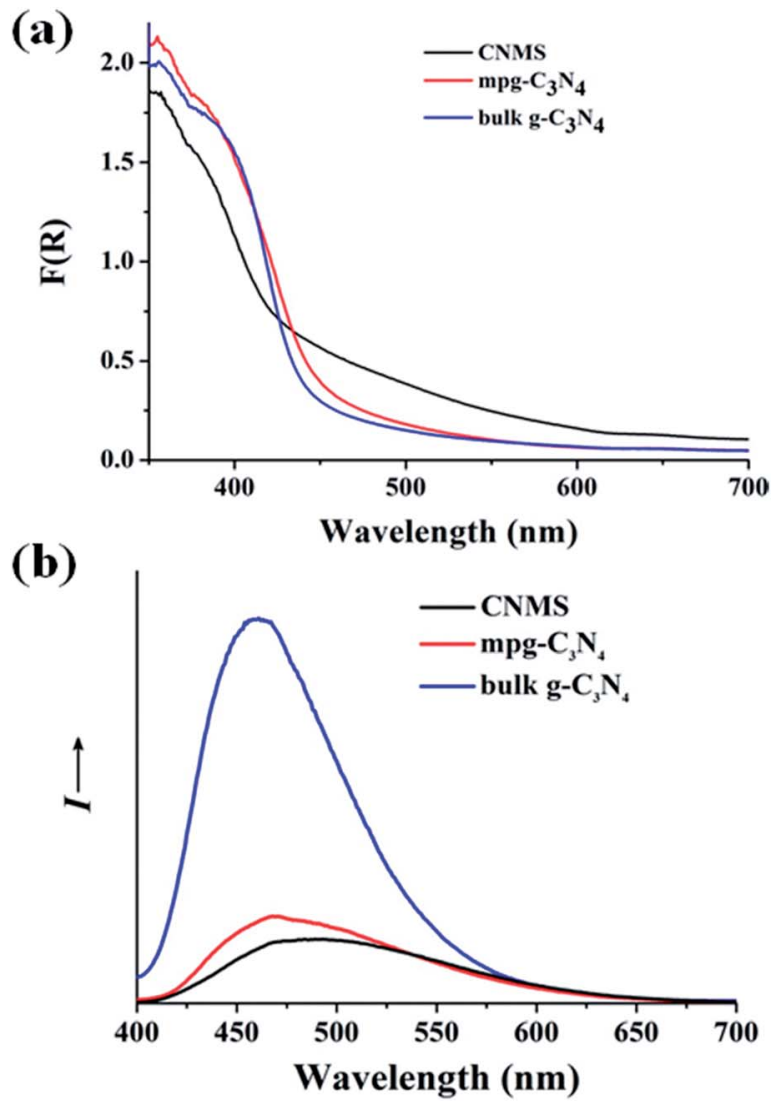

Fig. 3 (a) Optical absorption of CNMS, mpg- $\mathrm{C}_{3} \mathrm{~N}_{4}$ and $\mathrm{g}-\mathrm{C}_{3} \mathrm{~N}_{4}$ samples, respectively. (b) The photoluminescence spectra of CNMS, mpg- $\mathrm{C}_{3} \mathrm{~N}_{4}$ and $\mathrm{g}-\mathrm{C}_{3} \mathrm{~N}_{4}$ samples.

behavior. The slight blue shift of CNMS in the optical absorption relative to bulk $\mathrm{g}-\mathrm{C}_{3} \mathrm{~N}_{4}$ might be ascribed to the smaller structural size of the nanosheet building block (see Fig. 1c and S5 of ESI $\dagger$ ). The CNMS also exhibited a stronger absorption than two reference samples, especially in the 420-500 $\mathrm{nm}$ wavelength regions. A photoluminescence spectrum, coming from the recombination of free charge carriers, usually serves as a good technique for evaluating the processes of charge migration, transfer and separation. As illustrated in Fig. 3b, as compared to bulk $\mathrm{g}-\mathrm{C}_{3} \mathrm{~N}_{4}$, the substantially decreased fluorescence emission intensity of CNMS around $470 \mathrm{~nm}$ indicated the suppressed recombination rate of the photoinduced charge carriers, which is beneficial for further photocatalytic applications. ${ }^{26,41}$ The time-resolved photoluminescence spectrum was also employed to understand the photophysical behaviors of photoexcited charge carriers (Fig. S6 of the ESI $\dagger$ ). The fluorescence intensities of all three samples decay exponentially. A lifetime of $\sim 6 \mathrm{~ns}$ was obtained for CNMS at room temperature (298 K), which gives an estimate of the time for charges to reach the surface stabilized sites and the related structural length scales of a few nanometers.

Based on the above photo- and electrochemical investigation of CNMS, the photocatalytic NADH regeneration was performed. Optimum reaction conditions were adopted from our previous work. ${ }^{33}$ A reaction solution with a $\mathrm{pH}$ value at 8 in a 
phosphate buffer solution with $15 \%$ TEOA was employed. $\mathbf{M}$ is a homogeneous redox catalyst acting as a hydride transfer reagent to shuffle hydride to the $\mathrm{NAD}^{+}$. An active carbon nitride content of $3 \mathrm{mg}$ was maintained in all the experiments. The $\mathrm{NADH}$ regeneration was determined by measuring the increase of absorbance at $340 \mathrm{~nm}$ (with a molar extinction coefficient of $6220 \mathrm{M}^{-1} \mathrm{~cm}^{-1}$ ) using the Lambert-Beer law, as illustrated in Fig. S7 of the ESI. $\dagger$

The regeneration of $\mathrm{NADH}$ from $\mathrm{NAD}^{+}$is summarized in the reaction equation in Scheme 2. The photocatalytic activity comparisons among CNMS, mpg- $\mathrm{C}_{3} \mathrm{~N}_{4}$ and bulk $\mathrm{g}-\mathrm{C}_{3} \mathrm{~N}_{4}$ are presented in Fig. 4a. During the first illumination period, the conversion yields increase linearly. Under the same circumstances, typical well-known semiconductors such as $\mathrm{TiO}_{2}$ and $\mathrm{ZnO}$ were both inactive for $\mathrm{NADH}$ regeneration during the same

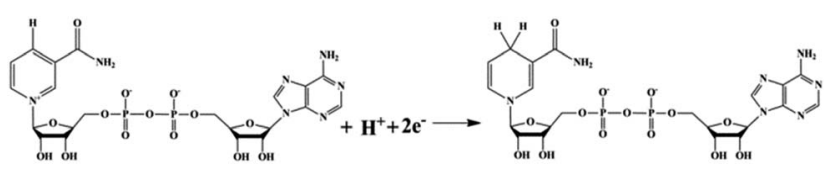

Scheme 2 The summarized reaction equation shows the regeneration of $\mathrm{NADH}$

\section{(a)}

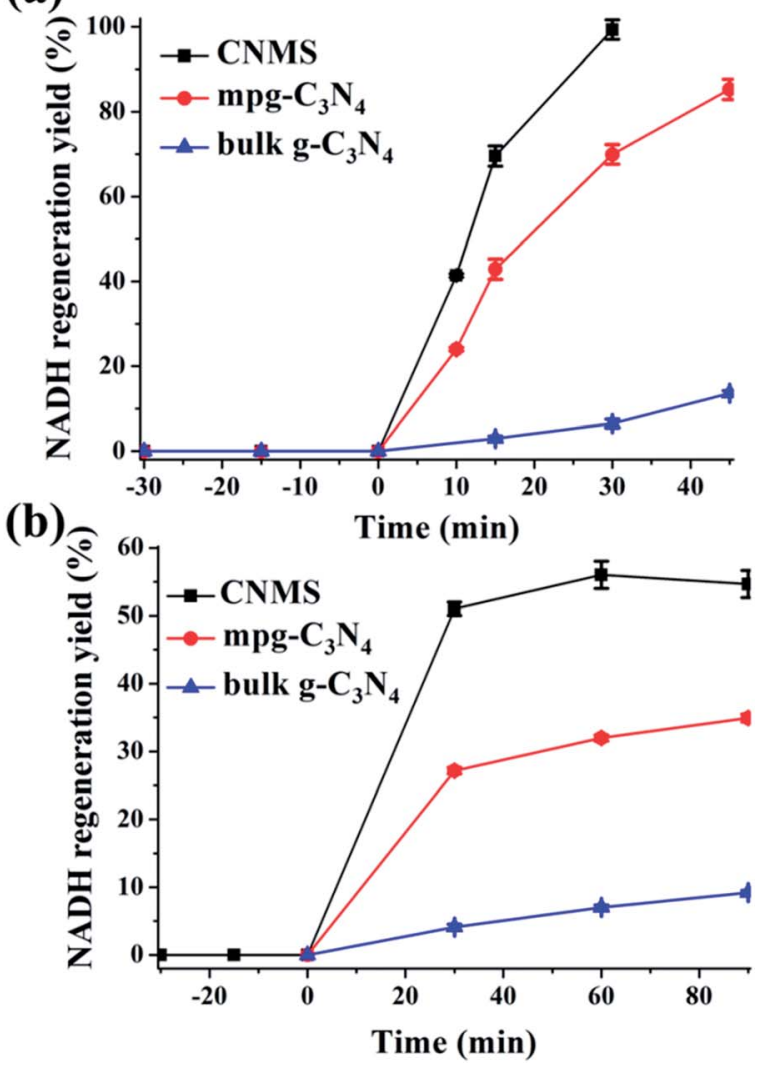

Fig. 4 (a) Photocatalytic NADH regeneration kinetics in the presence of $M(a)$ and mediator free (b) by CNMS, mpg- $C_{3} N_{4}$ and $g-C_{3} N_{4}$, respectively. For (a), mediator involved $\mathrm{NADH}$ regeneration: $\beta-\mathrm{NAD}^{+}, 1$ $\mathrm{mM}$; $\mathrm{M}, 0.25 \mathrm{mM}$; TEOA, $15 \mathrm{w} / \mathrm{v} \%$; PBS buffer, $0.1 \mathrm{M}, \mathrm{pH}=8$; carbon nitride, $3 \mathrm{mg}$; for (b), mediator free $\mathrm{NADH}$ regeneration: $\beta-\mathrm{NAD}^{+}, 1$ $\mathrm{mM}$; TEOA, $15 \mathrm{w} / \mathrm{v} \%$; PBS buffer, $0.1 \mathrm{M}, \mathrm{pH}=10$; carbon nitride, $3 \mathrm{mg}$. illumination time. For comparison, no NADH regeneration took place in the dark. CNMS gives the best performance, and the $\mathrm{NADH}$ conversion yield reached $100 \%$ after only $30 \mathrm{~min}$ light illumination. mpg- $\mathrm{C}_{3} \mathrm{~N}_{4}$ and $\mathrm{g}-\mathrm{C}_{3} \mathrm{~N}_{4}$ give $80 \%$ and $10 \%$ conversion yield within the same illumination period, respectively. Considering the even smaller surface area of CNMS compared to that of $\mathrm{mpg}_{-} \mathrm{C}_{3} \mathrm{~N}_{4}$ (see Fig. S4 $\dagger$ and Table 1), the higher activity can be ascribed to structural features which improve the light harvesting by inner reflections and field enhancement effects. ${ }^{\mathbf{4 2 - 4 4}}$ High efficiency light harvesting by CNMS leads to more light-generated electron carriers, which are subsequently transferred to $\mathbf{M}$ to couple with protons, and then shuffled to $\mathrm{NAD}^{+}$to create 1,4-NADH.

Even more striking, under alkaline reaction conditions $(\mathrm{pH}$ $=10$ ) the CNMS regenerates $\mathrm{NADH}$ in $50 \%$ yield without an electron mediator under light after only 30 minutes (Fig. 4b). This again demonstrates the excellent performance of CNMS as a photocatalytic system for $\mathrm{NADH}$ regeneration. The direct hydride transfer between CNMS and $\mathrm{NAD}^{+}$substrate is possibly promoted by the $\pi-\pi$ stacking interaction between adenine subunit of $\beta-\mathrm{NAD}^{+}$and the electron-rich, layered configurations of $\mathrm{g}^{-} \mathrm{C}_{3} \mathrm{~N}_{4}$, as the building blocks of CNMS. ${ }^{45-47}$ For the mpg$\mathrm{C}_{3} \mathrm{~N}_{4}$, a $50 \%$ conversion yield was only achieved after two hours' illumination. After 30 min illumination, only $25 \%$ of conversion yield was reached. It is worth mentioning that regeneration of $\mathrm{NADH}$ in the mediator free system is accompanied by the loss of stereospecificity, and the 1,6- and 1,4-isomers are formed simultaneously.

The mechanisms of photocatalytic NADH regeneration process and the photosynthetic light reactions are illustrated in Fig. 5a \& b, respectively. Under light excitation, CNMS generates electron-hole pairs. $\mathbf{M}$ can selectively regenerate 1,4-NADH by taking two electrons from the CNMS $(-1.3 \mathrm{~V} v s$. NHE, $\mathrm{pH}=7)$ followed by coupling with one proton and regiospecific transfer to $\mathrm{NAD}^{+}(-0.3 \mathrm{~V}$ vs. NHE) (see H NMR of $\mathbf{M}$ in Fig. S8 of the ESI $\dagger)$. More specifically, the electrons are transferred to $\left[\mathrm{Cp} * \mathrm{Rh}(\mathrm{bpy})\left(\mathrm{H}_{2} \mathrm{O}\right)\right]^{2+}$, producing $\mathrm{Cp} * \mathrm{Rh}(\mathrm{bpy})$, followed by coupling with one proton to form the hydriderhodium $[\mathrm{Cp} * \mathrm{Rh}(\mathrm{bpy})(\mathrm{H})]^{+}$, which acts as a hydride transfer reagent towards $\mathrm{NAD}^{+}$. Due to the coordination of ring-slipped $\eta^{3}$ $[\mathrm{Cp} * \mathrm{Rh}(\mathrm{bpy})(\mathrm{H})]^{+}$with the carbonyl-C-atom of oxidized $\mathrm{NAD}^{+}$, the enzymatically active $1,4-\mathrm{NADH}$ isomer is exclusively generated. The holes $(+1.4 \mathrm{~V} v s$. NHE) take their electrons from the oxidation of TEOA $(-0.84 \mathrm{~V} v s$. NHE), producing glycolaldehyde and di(ethanol)amine. ${ }^{21}$ The $\mathrm{g}-\mathrm{C}_{3} \mathrm{~N}_{4}$ network featuring tri-striazine units as building blocks and the molecular structure of the $\mathrm{NAD}^{+}$with the highlighted adenine subunit are presented in Fig. $5 \mathrm{c} \& \mathrm{~d}$, respectively. The $\pi-\pi$ stacking interaction leads to the hydride transfer from $\mathrm{g}-\mathrm{C}_{3} \mathrm{~N}_{4}$ to $\mathrm{NAD}^{+}$and the subsequent $\mathrm{NADH}$ regeneration but with poor selectivity for the enzymatically active 1,4-isomer. Upon taking the electron from CNMS, $\mathrm{NAD}^{+}$could be reduced to $\mathrm{NAD}^{\circ}$ and the free radical might undergo proton-assisted disproportionation to form 1,6-NADH. Only minor amounts of enzymatically active $1,4-\mathrm{NADH}$ can be obtained via the isomerization by non-enzymatic transhydrogenation between $\mathrm{NAD}^{+}$and 1,6-NADH. ${ }^{48,49}$ Due to the lack of substrate coordination as in the mediator involved system, 


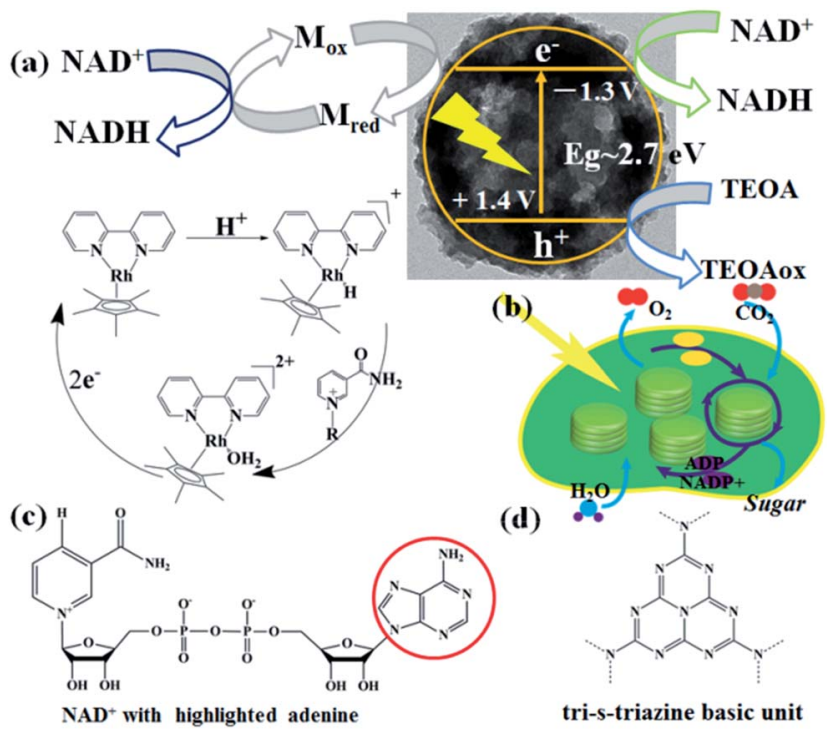

Fig. 5 (a) Schematic illustration of photocatalytic NADH regeneration by CNMS, including mediator involved system and mediator free system, respectively. The regeneration of catalytically active $[\mathrm{Cp} * \mathrm{Rh}(\mathrm{bpy})(\mathrm{H})]^{+}$was also illustrated, which acts as a hydride transfer reagent towards $\mathrm{NAD}^{+}$. (b) The thylakoid structure and $\mathrm{NADPH}$ involved functions in photosynthetic chloroplasts under light irradiation. (c) The molecular structure of $\beta-\mathrm{NAD}^{+}$with an adenine group highlighted in a red circle. (d) A perfect graphitic carbon nitride constructed from tri-s-triazine building blocks is illustrated.

the obtained mediator-free NADH regeneration is poor in selectivity. For overcoming the poor selectivity problem, experiments with metal-free biological mediators for NADH regeneration are currently in progress. ${ }^{50}$

Based on the above NADH regeneration and its mechanism analysis, we performed the photoenzymatic synthesis of L-lactate assisted by L-lactate dehydrogenase (EC 1.1.1.27). ${ }^{51}$ The synthesis of $\mathrm{L}$-lactate from pyruvate will provide a way to oxidize $\mathrm{NADH}$ to $\mathrm{NAD}^{+}$for glycolysis when no oxygen is present. The enzymatic reaction is depicted in Fig. 6 a.

Firstly, the as-regenerated NADH is used to reduce pyruvate in the presence of L-lactate dehydrogenase. The NADH absorbance peak at $340 \mathrm{~nm}$ vanished within 5 minutes after addition of pyruvate solution and L-lactate dehydrogenase, which means that NADH is completely consumed for the L-lactate formation (Fig. S9a of ESI†). The two peaks around $300 \mathrm{~nm}$ are due to the characteristic absorbance of $\mathbf{M}$ in aqueous solution. Fig. S9b of the ESI $\dagger$ shows the pyruvate reduction to lactate by commercial NADH assisted by L-lactate dehydrogenase, also reflecting the complete consumption of NADH in the enzymatic reaction (Fig. S10 of the ESI + ). The quantitative conversion demonstrates that the photocatalytically generated NADH is indeed in the active form (1,4-isomer), i.e. the artificial photosynthesis system produces a biologically accepted "currency".

The sustainable synthesis of L-lactate was achieved by coupling the mediator involved NADH photogeneration system with a redox enzyme, as illustrated in Fig. 6b. The stoichiometric conversion of pyruvate to lactate was accomplished after 6 hours' light illumination, using continuous reaction (a)

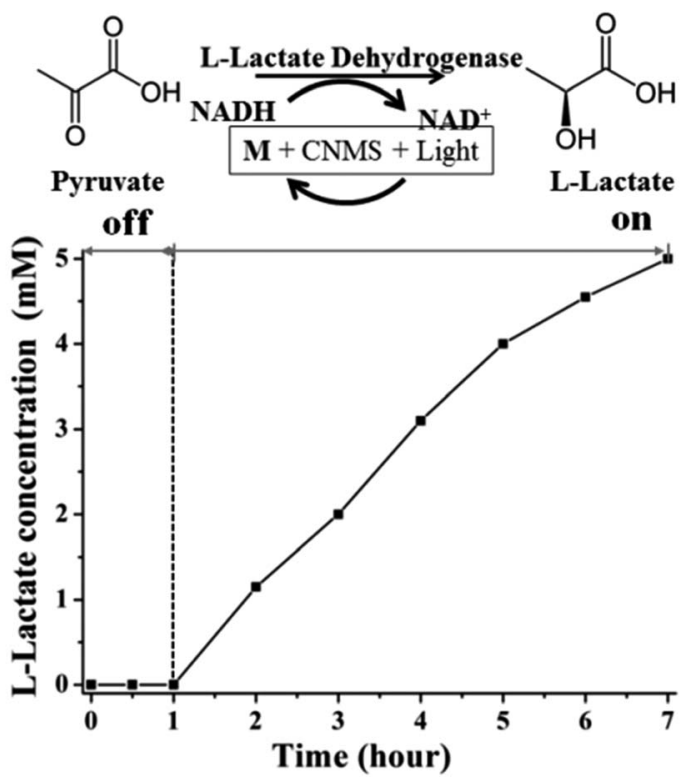

Fig. 6 (a) The conversion between pyruvate and L-lactate by L-lactate dehydrogenase. (b) Photocatalytically propelled enzymatic synthesis of L-lactate by CNMS in the presence of $M$ assisted by L-lactate dehydrogenase. Enzymatic reaction conditions: $\mathrm{NAD}^{+}(1 \mathrm{mM}), \mathrm{M}$ $(0.25 \mathrm{mM})$, pyruvate $(5 \mathrm{mM}), \mathrm{L}$-lactate dehydrogenase $(50 \mathrm{U}), \mathrm{pH}=7.0$ phosphate buffer with $15 \mathrm{w} / \mathrm{v} \%$ TEOA, 3 mg CNMS.

conditions. During the light reaction, the in situ regenerated NADH was immediately consumed by L-lactate dehydrogenase for the synthesis of $\mathrm{L}$-lactate from pyruvate, while the $\mathrm{NAD}^{+}$ could be repeatedly regenerated (the molar ratio of pyruvate to $\mathrm{NAD}^{+}$was chosen to be 5 , indicating that the NADH must be continuously regenerated for accomplishing the stoichiometric conversion). The yield was determined by the integration of NMR signals of the starting and ending reaction solutions, as shown in Fig. S11 of the ESI. $\dagger$ During the dark cycle, there is no L-lactate product detected. Complete conversion of pyruvate to L-lactate could be verified by the NMR spectra. Therefore, we can safely state that it is possible to realize the photoenzymatic synthesis of L-lactate from pyruvate in the presence of L-lactate dehydrogenase. Through a coupling with other enzymes, we can imagine synthesizing more valuable compounds, but also small fuel molecules such as methanol. ${ }^{52-56}$

\section{Conclusions}

In conclusion, we presented highly efficient cofactor regeneration systems which were synthesized by rational design and engineering of an existing photocatalytic system. Carbon nitride mesoporous spheres with a bioinspired inner structure were synthesized for the first time and employed as the catalyst for photocatalytic NADH regeneration in the presence of a hydride transfer reagent. The high surface area and strong light harvesting capability ensures that the CNMS possesses the highest activity for NADH regeneration in the examined series. In a mediator free system, the CNMS also gives the best performance for NADH regeneration but with poor 1,4 versus 1,6-selectivity. 
The in situ photocatalytically regenerated $\mathrm{NADH}$ could be coupled with L-lactate dehydrogenase for the synthesis of chiral L-lactate from pyruvate, and this reaction was run in a continuous fashion. This opens a general pathway for enzymatic synthesis of diverse chiral organic compounds, using ordinary light as the energy source. Owing to the facile synthesis and superior performance of CNMS, carbon nitride photocatalysis for NADH regeneration could turn compatible with the industrial demands for sustainable, high throughput synthesis. Furthermore, the silica-etching strategy for CNMS synthesis presented here could be extended to other nanomorphologies, the influence of which on reactivity stays unexplored here, as well as to other compositions of heterogeneous photocatalysts. The synthesis sequence developed here thereby might open further possibilities to engineer high efficiency artificial photosynthesis systems in the future.

\section{Acknowledgements}

J. L. acknowledges the support from Alexander von Humboldt Foundation. J. H. acknowledges the support from National Natural Science Foundation of China (21103095) and the Excellent Young Scientific Research Talents in University of Fujian, China (JA12285). Dr Guo Liang Li and Dr Changqing Ye are acknowledged for helpful discussions and experimental assistance.

\section{Notes and references}

1 J. Barber, Chem. Soc. Rev., 2008, 38, 185.

2 D. G. Nocera, Acc. Chem. Res., 2012, 45, 767.

3 H. Li, P. H. Opgenorth, D. G. Wernick, S. Rogers, T.-Y. Wu, W. Higashide, P. Malati, Y.-X. Huo, K. M. Cho and J. C. Liao, Science, 2012, 335, 1596.

4 F. Wang, W. J. Liang, J. X. Jian, C. B. Li, B. Chen, C. H. Tung and L. Z. Wu, Angew. Chem., Int. Ed., 2013, 52, 8134.

5 S. Fukuzumi, Phys. Chem. Chem. Phys., 2008, 10, 2283-2297. 6 S. Fukuzumi, K. Doi, A. Itoh, T. Suenobu, K. Ohkubo, Y. Yamada and K. D. Karlin, Proc. Natl. Acad. Sci. U. S. A., 2012, 109, 15572-15577.

7 M. L. Ghirardi, A. Dubini, J. Yu and P.-C. Maness, Chem. Soc. Rev., 2009, 38, 52.

8 S. J. Benkovic and S. Hammes-Schiffer, Science, 2003, 301, 1196.

9 P. Könst, H. Merkens, S. Kara, S. Kochius, A. Vogel, R. Zuhse, D. Holtmann, I. W. Arends and F. Hollmann, Angew. Chem., Int. Ed., 2012, 51, 9914.

10 S. Staudt, E. Burda, C. Giese, C. A. Müller, J. Marienhagen, U. Schwaneberg, W. Hummel, K. Drauz and H. Gröger, Angew. Chem., Int. Ed., 2013, 52, 2359.

11 H. K. Chenault and G. M. Whitesides, Appl. Biochem. Biotechnol., 1987, 14, 147.

12 K. Seelbach, B. Riebel, W. Hummel, M. R. Kula, V. I. Tishkov, A. M. Egorov, C. Wandrey and U. Kragl, Tetrahedron Lett., 1996, 37, 1377.

13 A. Bardea, E. Katz, A. F. Bückmann and I. Willner, J. Am. Chem. Soc., 1997, 119, 9114.
14 H. C. Lo and R. H. Fish, Angew. Chem., Int. Ed., 2002, 41, 478. 15 R. Wichmann and D. Vasic-Racki, in Technology Transfer In Biotechnology, Springer, 2005, p. 225.

16 W. Ma, D.-W. Li, T. C. Sutherland, Y. Li, Y.-T. Long and H.-Y. Chen, J. Am. Chem. Soc., 2011, 133, 12366.

17 F. Hollmann, B. Witholt and A. Schmid, J. Mol. Catal. B: Enzym., 2002, 19, 167.

18 Z. Jiang, C. Lü and H. Wu, Ind. Eng. Chem. Res., 2005, 44, 4165. 19 J. Ryu, S. H. Lee, D. H. Nam and C. B. Park, Adv. Mater., 2011, 23, 1883.

20 Y. Maenaka, T. Suenobu and S. Fukuzumi, J. Am. Chem. Soc., 2012, 134, 367.

21 S. S. Bhoware, K. Y. Kim, J. A. Kim, Q. Wu and J. Kim, J. Phys. Chem. C, 2011, 115, 2553.

22 S. Choudhury, J. O. Baeg, N. J. Park and R. K. Yadav, Angew. Chem., Int. Ed., 2012, 124, 11792.

23 J. H. Kim, M. Lee, J. S. Lee and C. B. Park, Angew. Chem., Int. Ed., 2012, 51, 517.

24 A. R. Parker and H. E. Townley, Nat. Nanotechnol., 2007, 2, 347. 25 X. Wang, K. Maeda, A. Thomas, K. Takanabe, G. Xin, J. M. Carlsson, K. Domen and M. Antonietti, Nat. Mater., 2008, 8, 76.

26 F. Goettmann, A. Fischer, M. Antonietti and A. Thomas, Angew. Chem., Int. Ed., 2006, 45, 4467.

27 Y. Wang, X. Wang and M. Antonietti, Angew. Chem., Int. Ed., 2012, 51, 68.

28 X. Zhang, X. Xie, H. Wang, J. Zhang, B. Pan and Y. Xie, J. Am. Chem. Soc., 2012, 135, 18.

29 G. Liu, P. Niu, C. Sun, S. C. Smith, Z. Chen, G. Q. Lu and H.-M. Cheng, J. Am. Chem. Soc., 2010, 132, 11642.

30 Y. S. Jun, J. Park, S. U. Lee, A. Thomas, W. H. Hong and G. D. Stucky, Angew. Chem., 2013, 125, 11289.

31 Y. Zhang, Z. Schnepp, J. Cao, S. Ouyang, Y. Li, J. Ye and S. Liu, Sci. Rep., 2013, 3, 2163.

32 S. Yang, Y. Gong, J. Zhang, L. Zhan, L. Ma, Z. Fang, R. Vajtai, X. Wang and P. M. Ajayan, Adv. Mater., 2013, 25, 2452.

33 J. Liu and M. Antonietti, Energy Environ. Sci., 2013, 6, 1486. 34 J. Toster, K. S. Iyer, W. Xiang, F. Rosei, L. Spiccia and C. L. Raston, Nanoscale, 2013, 5, 873.

35 J. Liu, J. Huang, D. Dontsova and M. Antonietti, RSC Adv., 2013, 3, 22988.

36 Q. Yang, M. Li, J. Liu, W. Shen, C. Ye, X. Shi, L. Jiang and Y. Song, J. Mater. Chem. A, 2013, 1, 541.

37 J. Liu, M. Li, J. Wang, Y. Song, L. Jiang, T. Murakami and A. Fujishima, Environ. Sci. Technol., 2009, 43, 9425.

38 J. Liu, G. Liu, M. Li, W. Shen, Z. Liu, J. Wang, J. Zhao, L. Jiang and Y. Song, Energy Environ. Sci., 2010, 3, 1503.

39 A. Zebda, C. Gondran, A. Le Goff, M. Holzinger, P. Cinquin and S. Cosnier, Nat. Commun., 2011, 2, 370.

40 Q. Zhang, T. Zhang, J. Ge and Y. Yin, Nano Lett., 2008, 8, 2867. 41 X. Wang, K. Maeda, X. Chen, K. Takanabe, K. Domen, Y. Hou, X. Fu and M. Antonietti, J. Am. Chem. Soc., 2009, 131, 1680.

42 Z. Dong, X. Lai, J. E. Halpert, N. Yang, L. Yi, J. Zhai, D. Wang, Z. Tang and L. Jiang, Adv. Mater., 2012, 24, 1046.

43 H. Li, Z. Bian, J. Zhu, D. Zhang, G. Li, Y. Huo, H. Li and Y. Lu, J. Am. Chem. Soc., 2007, 129, 8406. 
44 I. G. Yu, Y. J. Kim, H. J. Kim, C. Lee and W. I. Lee, J. Mater. Chem., 2011, 21, 532.

45 H. Zhou, Z. Zhang, P. Yu, L. Su, T. Ohsaka and L. Mao, Langmuir, 2010, 26, 6028.

46 M. V. Jose, S. Marx, H. Murata, R. R. Koepsel and A. J. Russell, Carbon, 2012, 50, 4010.

47 J. Moiroux, P. J. Elving and J. Electroanal, J. Electroanal. Chem. Interfacial Electrochem., 1979, 102, 93.

48 P. J. Elving, W. T. Bresnahan, J. Moiroux and Z. Samec, Bioelectrochem. Bioenerg., 1982, 9, 365-378.

49 Y. Ohnishi, Y. Kikuchi and M. Kitami, Tetrahedron Lett., 1979, 32, 3005-3008.

50 Y.-T. Long and H.-Y. Chen, J. Electroanal. Chem., 1997, 440, 239.
51 R. K. Yadav, J.-O. Baeg, G. H. Oh, N.-J. Park, K.-J. Kong, J. Kim, D. W. Hwang and S. K. Biswas, J. Am. Chem. Soc., 2012, 134, 11455.

52 R. Obert and B. C. Dave, J. Am. Chem. Soc., 1999, 121, 12192.

53 R. Cazelles, J. Drone, F. Fajula, O. Ersen, S. Moldovan and A. Galarneau, New J. Chem., 2013, 37, 3721.

54 T. Reda, C. M. Plugge, N. J. Abram and J. Hirst, Proc. Natl. Acad. Sci. U. S. A., 2008, 105, 10654.

55 T. W. Woolerton, S. Sheard, E. Reisner, E. Pierce, S. W. Ragsdale and F. A. Armstrong, J. Am. Chem. Soc., 2010, 132, 2132.

56 Q. Sun, Y. Jiang, Z. Jiang, L. Zhang, X. Sun and J. Li, Ind. Eng. Chem. Res., 2009, 48, 4210. 